\title{
Comment on: Meier JJ, Lin JC, Butler AE, Galasso R, Martinez DS, Butler PC (2006) Direct evidence of attempted beta cell regeneration in an 89 -year-old patient with recent-onset type 1 diabetes. Diabetologia 49:1838-1844
}

\author{
H.-L. Zhao \\ Received: 13 July 2006 / Accepted: 25 July 2006 / Published online: 2 September 2006 \\ (C) Springer-Verlag 2006
}

\section{To the Editor:}

The recent paper by Meier et al. [1] on pancreatic beta cell replication in type 1 diabetes was of great interest to me. Consistent with a prior study from the same group [2], the authors report that 'beta cell apoptosis is an important mechanism for beta cell loss in type 1 diabetes.' In addition, the authors claimed they provided 'direct evidence of attempted beta cell regeneration through the mechanism of beta cell replication in a case of newly diagnosed type 1 diabetes.' While the conclusions might be right, the data presented in the paper are not convincing.

The authors co-stained for cytoplasmic insulin (green), nuclear Ki67 (red) and nuclear 4,6-diamidino-2-phenylindole (DAPI) (blue) to identify and quantify replicated beta cells [1]. In this case, the replicated beta cell should show a purple (blue + red) nucleus and green cytoplasm. I was unable to identify any cell with a purple nucleus and green cytoplasm in the published Fig. 5. Instead, the arrow in Fig. 5a indicates a cell with an elongated red nucleus representing 'replicating beta cells.' The published Fig. 5b also shows several extra-islet elongated Ki67-expressing nuclei, which are suggestive of stromal fibroblasts. Compared with islet beta cells with round or oval nuclei, spindle fibroblasts have higher proliferative activity and are involved in the development of fibrosis [2]. If the Ki67expressing fibroblasts were counted as replicated beta cells, the morphometric data on beta cell replication would be inaccurate, and the conclusion that 'beta cell regeneration through the mechanism of beta cell replication' was taking

\section{H.-L. Zhao $(\triangle)$}

Department of Medicine and Therapeutics,

Prince of Wales Hospital,

The Chinese University of Hong Kong,

Shatin, New Territories, Hong Kong

e-mail: zhaohailu@cuhk.edu.hk place might not be justified. In both patients with type 2 diabetes [3] and type 1 diabetes [2], the authors have consistently claimed that the frequency of replication, assessed by staining with Ki67, is extremely low in beta cells.

The application of CD68 is an unreliable method for the identification and quantification of islet macrophages. The published Fig. 2 shows that the intra-islet CD68-expressing cells were counted as macrophages. But most of the CD68expressing cells are spindle cells, which are also highly suggestive of fibroblasts. In fact, both immunohistochemistry and flow cytometry have shown that fibroblasts test positive for a panel of CD68 markers [4]. CD68 is not a macrophage-specific antigen [5]. Rather, CD68 is a phagocytotic antigen, and activated fibroblasts and vascular smooth muscle cells and endothelial cells express CD68 [4-6].

The results of immunohistochemical staining and immunofluorescent labelling should be interpreted with extreme caution. False positive results occur through diffusion of immunostain into closely contacted cells, phagocytosis of apoptotic cell antigens by cells, and application of antibodies raised against short amino acid sequences [7]. Using confocal microscopy, a recent study showed membrane (yellow) immunoreactivity in a large proportion of human islet cells double-labelled for insulin (red) and glucagon (green) [8]. This observation does not indicate these membrane islet cells are alpha-beta cells that co-express insulin and glucagon. Instead, the yellow reflects label diffusion and close membrane contact between the islet beta cells and alpha cells. Similarly, the terminal deoxynucleotidyl transferase-mediated dUTP-biotin nick-end labelling (TUNEL)- and insulin-positive cells shown in Fig. 4 of the case presented by Meier et al. [1] may not represent apoptotic beta cells. Insulin-positive beta cells with phago- 
cytotic apoptotic bodies are also stained by TUNEL. The authors may argue that apoptosis has been assessed with TUNEL staining in a long list of publications. I respectfully suggest caution when interpreting image data. What I have learned from my 15-year experience in clinical and experimental pathology is that histology and immunostaining do have many limitations.

\section{References}

1. Meier JJ, Lin JC, Butler AE, Galasso R, Martinez DS, Butler PC (2006) Direct evidence of attempted beta cell regeneration in an 89year-old patient with recent-onset type 1 diabetes. Diabetologia 49:1838-1844

2. Meier JJ, Bhushan A, Butler AE, Rizza RA, Butler PC (2005) Sustained beta cell apoptosis in patients with long-standing type 1 diabetes: indirect evidence for islet regeneration? Diabetologia 48:2221-2228

3. Butler AE, Janson J, Bonner-Weir S, Ritzel R, Rizza RA, Butler PC (2003) Beta-cell deficit and increased beta-cell apoptosis in humans with type 2 diabetes. Diabetes 52:102-110

4. Kunisch E, Fuhrmann R, Roth A, Winter R, Lungershausen W, Kinne RW (2004) Macrophage specificity of three anti-CD68 monoclonal antibodies (KP1, EBM11, and PGM1) widely used for immunohistochemistry and flow cytometry. Ann Rheum Dis 63:774-784

5. Beranek JT (2005) CD68 is not a macrophage-specific antigen. Ann Rheum Dis 64:342-343 (author reply 343-344)

6. Andreeva ER, Pugach IM, Orekhov AN (1997) Subendothelial smooth muscle cells of human aorta express macrophage antigen in situ and in vitro. Atherosclerosis 135:19-27

7. Bendayan M (1995) Possibilities of false immunocytochemical results generated by the use of monoclonal antibodies: the example of the anti-proinsulin antibody. J Histochem Cytochem 43:881-886

8. Cabrera O, Berman DM, Kenyon NS, Ricordi C, Berggren PO, Caicedo A (2006) The unique cytoarchitecture of human pancreatic islets has implications for islet cell function. Proc Natl Acad Sci USA 103:2334-2339 